\title{
Probiotics in personal care products
}

Mei-Chiung Jo Huang ${ }^{1}$ and Jane Tang ${ }^{2^{*}}$

*Correspondence: jane.tang@noblis.org

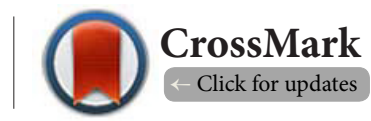

1 U.S. Food and Drug Administration, College Park, MD., USA.

${ }^{2}$ Noblis 3150 Fairview Park Drive South, Falls Church, VA., USA.

\begin{abstract}
In recent years, probiotics have attained popularity among consumers worldwide as a natural approach to maintain or restore human health. As a billion dollar industry, many products are already available in the market place with even more potential candidates in development. Knowledge gained from the Human Microbiome Project supports the utility of probiotics to achieve a balanced microbial community and potentially reduce or alleviate certain disorders. Most of the research studies and commercial probiotic products have focused on the human gastrointestinal tract; however, in the last few years interests and applications have extended to other physiological systems. Personal care products, which consist of overthe-counter drugs, cosmetics, and other consumer products, are used by almost everyone on a daily basis. Although the understanding and development of probiotics in personal care products is lagging behind the rapid progress that has been made in food products, recent studies have reported their potential uses in this market sector. This paper reviews recent findings related to microbial communities in the skin and oral cavity, where a large number of personal care products are applied, and discusses the opportunities and challenges of probiotics in these products.
\end{abstract}

Keywords: Probiotics, microbiome in skin, personal care products, microbiome in oral cavity

\section{Introduction}

The concept of probiotics was proposed in the early $20^{\text {th }}$ century by Elie Metchnikoff who postulated that ingested microorganisms could confer health benefits for humans [1]. These friendly or helpful bacteria may be the same or similar to species already residing in the human body. The World Health Organization has defined probiotics as live microorganisms that, when administered in adequate amounts, confer a health benefit [2]. Probiotics have been available in yogurts, dietary supplements, and other products for years. Recent interest by consumers, in promoting health naturally, has boosted sales and a new generation of products worldwide. Currently, probiotics are a multi-billion dollar industry with an estimated $7 \%$ growth projected globally $[3,4]$.

While commercial products and applications of probiotics continue to expand, scientific evidence and clinical studies supporting various health claims have not kept up with their pace [1]. Many probiotic claims have been based on preliminary assessments, uncontrolled studies, and at times anecdotal observations or simply speculation [2]. There are myths and misconceptions regarding the definition and benefits of probiotics [5]. Furthermore, commercial probiotics for human and animal use are often labeled inaccurately, raising serious concerns among researchers and consumers [6].

Nevertheless, the past decade has witnessed many studies regarding the role of probiotics in treating gastrointestinal (Gl) disorders. Advanced technologies in genome sequencing have enabled functional studies to identify a number of microbial communities in the human body and their roles in health and diseases. This knowledge augmented with various molecular studies has allowed a more comprehensive view of probiotics and their effects. Different mechanisms have been found to account for the possible health effects of probiotics; these include reducing harmful organisms, producing antimicrobial compounds, and stimulating the host's immune responses [1].

As studies on probiotics and products targeting GI microbial communities continue to grow, potential applications are being considered in personal care products, such as lotions, creams, and toothpastes [3]. For years the skin care industry has been investigating probiotics to enhance the function 
Huang et al. Microbiology Discovery 2015,

and beauty of the skin, and researchers have been assessing whether probiotics could be used to treat certain skin conditions $[4,7,8]$. There are also reports indicating the potential of probiotics to combat tooth caries [2]. It is anticipated that the trend of including probiotics in personal care products will continue to grow.

According to the Office of Cosmetics and Colors in U.S. Food and Drug Administration (FDA), the term "personal care products" does not have a legal or regulatory definition, but usually refers to a wide variety of products found in the health and beauty departments of drug and department stores [9]. They may fall into a number of different categories (cosmetics, drugs, medical devices, and dietary supplements) that are regulated under the Federal Food, Drug, and Cosmetic Act (FD\&C Act), or may be regulated as other types of consumer products under the Consumer Product Safety Act.

Under the FD\&C Act, a product's category is based primarily on intended use. For example, the term "cosmetics" is defined in section 201 (i) of the FD\&C Act in part as "articles intended to be rubbed, poured, sprinkled, or sprayed on, introduced into, or otherwise applied to the human body or any part thereof for cleansing, beautifying, promoting attractiveness or altering appearance"; "drug" is defined in 201 (g) of the FD\&C Act Section in part as "articles intended for use in the diagnosis, cure, mitigation, treatment, or prevention of diseases" or "articles intended to affect the structure or any function of the body" [10]. Some products meet the definitions of both cosmetics and drugs when they have two intended uses. For example, a shampoo is a cosmetic because it is intended to cleanse the hair. An antidandruff treatment is a drug because its intended use is to treat dandruff. Consequently, an antidandruff shampoo is both a cosmetic and a drug. Another example is a mouthwash containing a microorganism (Streptococcus salivarius) is expected to reduce odor in individuals with bad breath.

This article provides an overview of probiotics use in personal care products. The discussion starts with a brief review of microbial communities in the skin and oral habitat. Their role in the health status of the host is further illustrated by examples of diseases associated with changes of microbial populations. The following section focuses on the potential of probiotics in personal care products, including those that may help to prevent disorders or restore health in the skin and oral cavity. In the last section of this review, we focus our discussion on the challenges (substantiating claims by research, differences in regulations applied to different product categories by different countries) and future directions which might be impacted by the increasing interest in probiotics in personal care products.

\section{Review}

\section{Microbiota in health and diseases}

The understanding of human microbiota, or the microbial community residing in the human body, has increased substantially as a result of the Human Microbiome Project (HMP)
[11]. Realizing microbial populations outnumber human cells by a factor of 10 in our body, the National Institutes of Health $(\mathrm{NIH})$ initiated HMP in 2007 to assess microbiota in Gl tract, skin, oral cavity, nares, and vagina (in females) [12-14]. Advances in genomic technologies and computational methodologies allow a comprehensive characterization of microbial compositions, including those that cannot be cultivated on microbiological media [15-18]. The HMP concluded in 2012 with numerous findings published from this five-year study [14]. The overall microbial diversity is extensive regardless of the site surveyed, and each system has dominant groups of organisms reflecting its special niche [13]. The microbiota experience variations through life that are affected by internal (host health) and external (environmental) factors [19]. In general, microbial community differences within an individual (intrapersonal) are smaller than that between individuals (interpersonal) $[16,20]$.

Among the goals of HMP, understanding the role of microbiota in the health status of the host is undoubtedly one of the top priorities $[\mathbf{1 2}, \mathbf{1 4 , 1 5 , 2 1 ]}$. In the past, microbial diseases focused on individual pathogens; the more recent approach is generally assessing microbial communities and their interactions with the host to gain a better understanding of the health condition of an individual. A number of studies have revealed that dysbiosis, a disturbance in the microbial ecosystem, is responsible for various diseases and disorders. The Gl system is perhaps the best studied site in the HMP and yielded valuable scientific insights. Metagenomic analyses of gut microbiome demonstrated many incidences that link the shift of populations with illnesses and disorders; these include different types of diarrhea (e.g., acute, traveler's, and antibiotic-associated), irritable bowel syndrome, Crohn's disease, obesity, and other conditions $[\mathbf{4 , 1 1 , 2 2 - 2 5 ]}$. On the other hand, microbiota from healthy individuals has been attributed to potentially fighting against obesity and playing a role insevere malnutrition conditions, as shown by recent research findings $[\mathbf{2 6 , 2 7 ]}$.

\section{The skin microbiome}

The skin is the largest organ in the human body. Its primary function is to protect our bodies from external harm by acting as a physical barrier, with additional roles that include regulation of body temperature, evaporation control, sensation, and storage of lipids and water $[\mathbf{2 0}, \mathbf{2 8}]$. As an interface between internal organs and the outside environment, the skin is always in contact with different substances. Microorganisms including bacteria, fungi, and viruses found everywhere often colonize the skin. They can generally be categorized into three groups: 1) transient microbes present intermittently, 2) temporary organisms that persist over a short period of time, and 3) residents that permanently inhabit the skin $[9,29]$. Additionally, skin continuously undergoes self-renewal, so resident microbial cells are shed in the process. Most of the microbes found on the skin are commensal organisms and harmless to healthy individuals; in fact, some are considered mutualistic 
organisms and confer health benefits to the skin by secreting antibacterial substances, preventing pathogen colonization, and influencing host immune responses [30]. On the other hand, commensal microorganisms can cause diseases and infections if the physical barrier has been compromised due to trauma or injuries $[15,20]$. Some are considered opportunistic pathogens that become infectious agents when the host is immunocompromised due to surgeries, treatment, or other confounding factors [31,32].

Historically, microorganisms that colonized the skin were thought to be limited in their types based on culturing methods [9]; these were primarily Staphylococcus epidermidis and other coagulase negative staphylococci as well as species of Corynebacterium and Propionibacterium [28,33]. The development of molecular techniques, such as metagenomic analyses, since revolutionized the ability to determine microbial composition on the skin, including those that cannot be cultivated on microbiological media $[15,16,19]$.

Various factors affect the microbial flora of the skin and they can be generally categorized into host and environmental factors [28]. The skin microbiome is highly dependent on the microenvironment of sampled site, a reflection on the physiology of skin $[16,28]$. Sebaceous sites such as the forehead have the lowest diversity, and Propionibacterium species are the dominant organisms. On the other hand, moist areas (e.g., armpits, navel, groin) constitute higher diversity of microbiota, with Staphylococcus and Corynebacterium species as the predominant members $[16,28]$. Moreover, skin sites with greater bacterial diversity (e.g., forearm, hand, buttock) can harbor diversity as high as or higher than that of the gut microbiome. The acidic condition resulting from sebum degradation discourages pathogens from invading and establishing in the skin [28]. Personal hygiene is another environmental factor that has a direct effect on the skin's microbial flora. Soaps, makeup, and skincare products (e.g., moisturizers) alter skin conditions that in turn may influence the types of microbes residing on the skin. More discussion on this topic is covered in Probiotics and Skin Health section.

Among the host factors are age, sex, and anatomic sites. Skin microbiota differ among various age groups, with significantly different bacterial communities between the youngest and the oldest groups [19]. A newborn acquires resident bacteria on the skin soon after birth, and their composition is affected by birth delivery methods $[20,30]$. Hormonal changes during puberty stimulate the growth of lipophilic (or lipid-loving) bacteria due to sebum production [19]. Physiological changes and anatomic differences also contribute to microbial community variance between genders [16].

Altered lipid composition and organization can cause skin diseases when commensal bacteria become infectious agents. One such example is acne, an inflammatory malady that affects $80 \%$ of adolescents in the U.S. [31]. The change of lipid composition during puberty encourages lipophilic organisms, such as Propionibacterium acnes, to proliferate [25].
As these bacteria derive energy from metabolizing fatty acids in the sebum, a variety of enzymes are secreted that injure the tissue lining of sebaceous glands. In conjunction with activated immune responses, this results in a skin condition termed acne vulgaris [28]. In addition, the investigators noticed younger children had a higher abundance of Staphylococcus (S.) aureus, which were later replaced by lipophilic and other bacteria. This finding may have important implications for skin disorders, such as atopic dermatitis (or eczema), which are more prevalent among children but often resolves by adolescence and adulthood [34]. Further,diseases of the skin often result from reduced barrier function [20]. S. aureus is one of the most commonly cited skin pathogens, and it is responsible for several cutaneous infections such as impetigo, furuncles, subcutaneous abscesses, ulcers, and other more serious systemic infections when penetrating into the blood stream (e.g., toxic shock syndrome) $[20,31,33]$. Burn victims whose epidermis (and at times dermis as well) have been destroyed are exposed to various assaults. During the first 48 hours, Gram positive bacteria (e.g., S. aureus) are the main colonizers. A shift then occurs and Gram negative opportunistic organisms predominate, some with virulent properties that can cause life threatening infections [35]. In addition, there are dermatological disorders that have been associated with skin microbiota $[\mathbf{1 5}, \mathbf{2 5}, \mathbf{2 8}, \mathbf{3 4}]$. Atopic dermatitis $(A D)$ is a chronic and intensely inflammatory skin disorder that has more than doubled in industrialized countries in the past three decades without a clear cause [28]. AD patients frequently acquire cutaneous infections with $S$. aureus as the main colonizing organism. A study that analyzed microbiome from three groups of people found a strong association between disease severity and bacterial diversity [34]. In general, the disease was most severe when community diversity was low; as microbiota increased after treatment, they approached a level of diversity similar to those from healthy skin. The shift of relative abundance of microbial community members was a complex process, further stressing the importance of a comprehensive assessment in treating AD cases [25,34].

Determination of skin microbiota was conducted for psoriasis, another cutaneous disorder. The cause for this chronic inflammatory condition of the skin affecting approximately $2 \%$ of the population worldwide is largely unknown. Applying molecular techniques, differences in colonization patterns between psoriasis lesions and uninvolved skin sites were noted [30]. The distributions of the three major skin microflora differed significantly in their representations, suggesting a substantial ecological disturbance of microbial population contributed to the psoriasis condition in patients.

Chronic non-healing wounds are a frequent challenge for people, because prolonged healing increases the risk of bacterial colonization with possible deleterious effects. A longitudinal study on microbiota in diabetic mice indicated a qualitative and quantitative shift in bacterial species colonizing the diabetic skin, and this change favored species such 
Huang et al. Microbiology Discovery 2015,

as Staphylococcus [33]. Not surprisingly, this shift in bacterial community coincided with impaired healing of the wound, and Staphylococcus species have been implicated in both impaired wound healing and leg ulcers [36].

These examples illustrate that dysbiosis in the skin habitat is a key player in shifting from a healthy condition to some type of disorder. Restoring homeostasis is a holistic approach to treat certain skin diseases.

\section{Oral microbiome}

Similar to the skin, the oral cavity actively interacts and connects with the external environment. As a major gateway to the human body, food enters the mouth and air passes through on its way to the lung. Unique to the oral cavity are two types of surfaces for bacteria to colonize: the hard surface of the teeth and the soft tissue of the oral mucosa [37]. Distinct habitats include teeth, gingival sulcus, tongue, cheeks, hard and soft palates and tonsils. Each niche provides surfaces and functions, atmospheric conditions, and nutrients for certain microbial population to flourish and establish $[37,38]$. As a result, the oral bacterial communities are complex and harbor approximately 1000 species with the majority identified by molecular methods (i.e., 16S rRNA sequencing) [39], making this habitat one of the most diverse microbiomes in human body [40].

The dynamic interaction with the external environment makes oral microbiota unique in facing certain challenges not present in other human systems; the multiple functions (e.g., eating, talking, smoking) carried out in the oral cavity may affect bacterial growth and persistence [38]. Certain foods rich in carbohydrates contribute to biofilm formation on both hard and mucosal surfaces of the oral cavities that can shelter both pathogens and commensal microflora. Saliva supports the dynamic flow of nutrients and other ingested materials (such as antimicrobials) in the oral cavity. Additionally, hygiene practices such as tooth brushing and mouth rinsing disrupt microbiomes due to agitation and dislodging from their adhesion sites $[37,40]$.

Not surprisingly, microbial communities play an important role in oral health. Studies have indicated that biodiversity is crucial to maintaining good dental health, as demonstrated by comparing microbiomes in plaque and saliva between healthy and symptomatic individuals $[40,42]$. In general, oral health is achieved by balanced and diverse microbial communities that interact in mutualism with its host [38]. The higher diversity indicates that different species are responsible for certain functions required to maintain homeostasis within the oral cavity $[20,37,40,42]$.

As with other ecosystems in the human body, shifts in oral microbial populations favor pathogens to predominate or result in decreased biodiversity. Factors contributing to ecological shifts include poor oral hygiene, immunological disorders, and certain genetic compositions that predispose individuals to infections [37]. Diseases resulting from oral ecosystem change include dental caries (tooth decay), periodontitis (gum inflam- mation), endodontic (root canal) infections, alveolar osteitis (dry socket) and tonsillitis [37,39,41]. Although halitosis (bad breath) is not a serious medical condition, the source could be anaerobes flourishing in the tongue mucosal area and producing volatile sulfur compounds $[38,43]$. Additionally, there are associations between oral pathogens and systematic diseases, such as diabetes, stroke, and cardiovascular disease $[37,39]$. All these undesired conditions underscore the key role the oral microbiome plays in human health.

Dental caries and periodontal diseases are the two most prevalent oral diseases worldwide $[\mathbf{3 8 , 4 5}$. Tooth decay affects all ages and is not limited to developed countries. As the primary cause of oral pain and tooth loss, this disease initiates when an individual repeatedly ingests high level of carbohydrates, resulting in oral microbiota shifted to acid producing microbes (e.g., species of Lactobacillus and Streptococcus) [40]. As biofilm matures on teeth, these organisms accumulate in dental plaque and lower the $\mathrm{pH}$ of the oral cavity. Opportunistic pathogens such as Streptococcus mutans take advantage of the environment and ferment carbohydrates, producing more acid by-products that further destroy the enamel and root of the tooth [37]. If left untreated, lesions can further progress into the pulp and cause it to become infected by anaerobic bacteria with proteolytic properties [40]. These endodontic infections are more serious and often are precursors to periodontal diseases.

Periodontal diseases are an inflammatory disorder of the periodontium, the specialized tissue that surrounds and supports the teeth. Gingivitis, the milder form, is perhaps the most commonly encountered oral diseases in adults $[37,40,41]$. Bacteria adhere to the tooth surface via dental plaque that is continuously being formed, and shifting from mostly Gram positive aerobes and facultative anaerobes to Gram negative anaerobes; this results in irritation and inflammation of the gum (gingiva). This disease, however, is reversible by removing dental plaques through good oral hygiene [40].

Once the attachment between gingivae and teeth is gone, periodontal pockets are formed that allow a number of anaerobic bacteria to colonize. As the infection progresses, tissue damage leads to teeth being motile in their sockets and eventually tooth loss [37]. Periodontitis can give rise to serious health concerns; left untreated, it may lead to systemic conditions with life-threatening consequences. Recent genome sequencing efforts have indicated that specific microbiota (e.g., Porphyromonas gingivalis, Treponema denticoal, Tannerella forsythia) are associated with advanced periodontitis $[37,41]$.

\section{Probiotics}

With a better understanding of dysbiosis as the underlying cause for many diseases and disorders, restoring and maintaining a healthy microbiota is gaining wide support as a treatment and prevention approach in this post-antimicrobial era. The most noticeable development in this area is probiotics-beneficial microorganisms that, when administered in adequate 
amounts, can confer a health benefit on the host $[\mathbf{1 , 2 , 6 ]}$. In recent years, numerous products containing probiotics have entered the marketplace; these include naturally fermented and not-fermented food products, dietary supplements, approved pharmaceutical products, cosmetics, hygiene items, and other products, such as household cleaners $[1,3,45]$. Although there is no generally accepted definition for the word "natural", promoting health in such a way is appealing to consumers worldwide with sales projected into the billions of dollars $[3,4,46]$. The users are not only limited to humans; probiotics have been applied regularly to animal feeds to boost livestock production, and the potential utility of probiotics in the aquaculture industryis also being explored $[6,47,48]$.

Studies and clinical trials have been conducted to determine the effect of probiotics and the mechanisms of action in the Gl system; these include strengthening and maintaining the intestinal barrier, modulating immune responses, enhancing microbial flora, producing antimicrobial substances, degrading

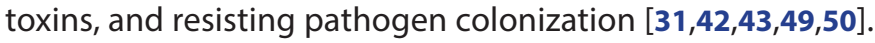
Most of the probiotics are lactic bacteria belonging to Lactobacillus and Bifidobacterium, as well as other bacterial genera and yeasts (e.g., Saccharomyces) $[\mathbf{1 , 3 , 4 , 7 , 5 1 ]}$. The prophylactic effect of probiotics has been reported and encouraged after surgery to prevent Clostridium difficile infection [2]. Additionally, probiotics have met with some success in treating disorders such as acute diarrhea, pouchitis (recurrent inflammatory condition in the ileal pouch), irritable bowel syndrome, ulcerative colitis, cancer of the Gl system (e.g., colorectal, bladder) and urogenital infections $[3,25,31,47,52]$. Due to the significant potential for treating $\mathrm{Gl}$ disorders, a number of products are marketed with claims to promote $\mathrm{Gl}$ health by balancing the microbiota in this system $[\mathbf{5 , 5 3}]$.

\section{Probiotics and skin care}

Until recently, the beneficial effects of probiotics have been mostly focused on the Gl system. In the last few years, however, there have been reports on the potential use of probiotics

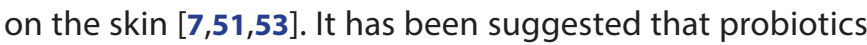
ingested orally exerted their effects on the skin via mechanisms initiated in the gut, mostly due to changes in systemic immune responses such as modulating specific T-cells and stimulating toll-like receptors $[4,7,31,47]$. Atopic dermatitis and eczema are perhaps the most widely studied disorders in which probiotics have been used $[2,3,51]$. For instance, oral administration of Lactobacillus species was reported to be effective in managing inflammation $[47,55,56]$; however, the efficacy in infants and young children varied $[2,57]$. In the case of psoriasis where dysbiosis was associated with skin inflammation, probiotics have been suggested to restore commonly occurring resident microbes that were diminished when the disorder was present [30]. Other reported benefits to the skin from the ingestion of probiotics include the healing of burns and scars, rejuvenating skin tissues, protection against ultraviolet rays, and improving innate immunity of the skin $[8,51,58]$.
Industries involved in personal care products have assessed probiotics as "bioactive ingredients" to help enhance the beauty as well as the function of the skin $[4,10,59]$. These products range from topical applications (e.g., body lotion, anti-aging serum, soap, aftershave, wipe) to ingestible products (e.g., probiotic drinks) $[3,8,45]$. Lactobacillus is the most common bacterial genus listed in the ingredients [4]; others with less specific descriptions (e.g., probiotic enzyme, ferment lysate, probiotic proteins) have implied association with some type of beneficial organisms. In a few cases bacterial metabolites (e.g., lactic acid, hyaluronic acid) are listed as ingredients [51]. The beneficial effects exerted by probiotic organisms via topical application are mostly circumstantial evidence [7]. Proposed mechanisms of action from scientific papers include improving barrier function of the epithelium layer and competitive exclusion (i.e., growth inhibition by limiting nutrients and producing antibiotics) of pathogens [47].

Safety limits for viable organisms in products other than food are usually very low. For example, the current FDA acceptable limits for total (not pathogenic) microorganisms in cosmetics are 500 colony forming units (cfu) per gram in eye-area products and $1000 \mathrm{cfu} / \mathrm{g}$ for other area products [60]. It is doubtful that such low number of live cells could exert beneficial effect, not to mention the technical challenge of maintaining viability after manufacturing and storage. The cosmetic formulas are usually complex containing a number of ingredients, including preservatives to discourage microbial growth. Typically, preservatives having broad-spectrum antimicrobial efficacy are combined with one or more compounds of more selective efficacy in order to deliver a broad antimicrobial effect against a wide range of potential contaminating microorganisms; and at the same time establish some degree of synergic activity [61]. Even if the safety limits are relaxed, concentrating cells and maintaining their long term viability in personal care products pose technical challenges for industries.

Because incorporating viable beneficial microorganisms adds complexity to the formulation and manufacturing processes, some cosmetic companies are addressing these issues by taking an alternative approach to probiotics. Instead of live microorganisms, only their "bio-active" molecules or metabolites may be used in cosmetic products. These socalled "novel technologies" draw from research on various fermentation-based proteins, filtrates, and lysates that reportedly retain beauty benefits without the presence of whole or live bacteria [8]. Papers have been published, suggesting possible effects of probiotics on the cellular activities of the skin, such as enhancement of respiration, energy generation, and stress responses [4]. A review by Lew and Liong summarized cellular components or microbial metabolites (i.e., bioactives) as probiotics in dermal applications. According to their review, lactic acid serves as a moisturizing factor, hyaluronic acid improves skin hydration and elasticity, and sphingomyelinase generates ceramide for skin barrier function. 
Huang et al. Microbiology Discovery 2015,

In addition, lactic acid, acetic acid, and diacetyl are reported to have a preservative effect. However, claims for effects such as skin protection and cellular structure or function may render a product a drug under the FD\&C Act, not a cosmetic, as noted in the introduction. Refer to Conclusion and future directions section for further discussion of product regulations [51].

Nevertheless, scientific evidence is generally lacking to support the overall benefits of probiotics in cosmetics. In contrast with the vast amount of literature addressing probiotic effects on Gl disorders, research pertaining to probiotics in cosmetics is still in its infancy. The few clinical trials conducted by the cosmetic companies to address benefit have had limited value because the studies were performed either in vitro or only with a small sample size $[\mathbf{1 , 5 8}]$. The use of probiotics in personal care products are anticipated to continue; collaboration between researchers, industries, and regulatory agencies is instrumental in making advances in this field [8].

\section{Probiotics and oral care}

Good hygiene has been recognized as the most effective approach to control oral diseases. In developed countries, dental caries in children are preventable by proper oral hygiene, diet, and fluoride exposure. People worldwide understand that removing dental plaque, by brushing with toothpaste or using chewing sticks, is important for oral health $[37,40,42]$.

Applying probiotics to improve oral health is a relatively new area that is gaining momentum in recent years by researching into its effectiveness and safety $[37,44,62,64]$. Some have followed the traditional GI probiotic approach by ingestion; others have considered applying probiotics to oral care products and hygiene practices to prevent tooth decay and other oral health problems, such as gingivitis and periodontitis $[1,64]$. Several studies have shown that directly adding probiotics to oral care products or practices had positive effects. For example, probiotic organisms have been included in toothpastes to target Streptococcus (St.) mutans responsible for dental caries and plaques around orthodontic brackets $[63,65]$. Meswak, a plant native to the Middle East that has an inhibitory effect on St. mutans, has been used for tooth cleaning in the region. In combination with Lactobacillus rhamnosus, it further reduced the level of St. mutans in saliva [42]. In another study, including indigenous species of Streptococcus in mouthwash reduced the level of pathogens in saliva and subgingival plaques. Because these organisms were part of the normal flora, rinsing regularly did not pose safety concerns [44]. Several studies have indicated that St. salivarius was effective in reducing the severity of malodor in individuals with halitosis $[40,43]$.

Companies are working toward adding probiotics to toothpaste and other oral products, such as chewable tablets, gums, and lozenges, to fight tooth decay, gingivitis, and bad breath $[3,62,65]$. As with skin care products, scientific evidence of efficacy for probiotics in oral products is limited. A few hypothetical mechanisms of action have been proposed; these include guarding oral health by competing for nutrients, preventing pathogens colonization by secreting antimicrobial substances, modulating immune functions, and maintaining homeostasis in the oral cavity $[47,65]$. Some suggested that probiotics show promise as clinical application for dental caries [1,2]; if taken into effect,more evidence of efficacy will become available in the near future.

\section{Conclusion and future directions}

Probiotics continue to expand in applications and market share, and this exponential growth is not likely to subside. However, the biggest shortcoming in the use of probiotics is the lack of scientific evidence and clinical studies for specific health applications [1,52]. Many probiotic claims for food have lost credibility because they were based on preliminary assessments and anecdotal observations, and personal care products are not exempt from the same trends and misconceptions. Furthermore, the beneficial effects touted by industry and others making such claims appear to be straindependent $[3,5]$. Unfortunately, the positive outcomes have been generalized and conveyed to consumers (and even to health professionals) without adequate data [6]. To further complicate the matter, products on the market often contain multiple microorganisms; making the data and deciphering the role of each strain a challenge [3].

Additionally the data on safety, specifically the long-term impact of probiotic organisms on existing microbiomes and overall health, is lacking $[3,29]$. This raises a concern for young children and those with underlying health conditions who may be at risk of experiencing serious and unexpected consequences [1].

Regulatory requirements are another challenge in marketing personal care products containing probiotics. As mentioned earlier, these products may fall into a number of different product categories (cosmetics, drugs, medical devices, and dietary supplements) that are regulated differently under the FD\&C Act, or be regulated as other types of consumer products. For example, drug products must generally either receive premarket approval by FDA through the New Drug Application (NDA) process or conform to a "monograph" for a particular drug category as established by FDA's Over-theCounter (OTC) Drug Review, while cosmetic products are subject only to post-market surveillance [66].

Worldwide variations in regulatory framework regarding probiotics cause further complications for research and industry. The European Food Safety Authority (EFSA) rejected nearly all health claims for benefits of probiotic bacteria; consequently, companies cannot mention the health benefits of their products based on the probiotic content $[3,46]$. This action raised concerns among some scientists and clinical investigators that it sent negative messages to consumers and that years of research regarding the benefits of probiotics would thus be wasted. They communicated their objections to EFSA, and requested that EFSA consider a more realistic 
standard of evidence for these products $[67,68]$. Other countries may be more lenient in their regulations. For example, Canada recently approved a patented probiotic formula to treat C. difficile infections in hospitalized patients. South Africa is proactively reviewing regulations regarding probioticcontaining products to ensure that "the manufacturers... be held responsible for providing the consumer with scientifically sound and legally correct information" [69]. In Asia, the Indian Council of Medical Research came up with a set of guidelines for evaluating an influx of probiotic products into their country [70]. Although Japan has one of the largest functional food markets globally, it considers probiotics as Food for Specified Health Uses (FOSHU) and has approved relatively few products in the category of "foods to modify gastrointestinal conditions" $[3,71]$. Until recently China has been tolerant of products with various health claims; since the enactment of the Food Safety Law in 2009, regulation has tightened and explicitly required human clinical data. These examples indicate the international community's awareness of the importance of accurate health claims and realize the disparity of various probiotic products. The regulatory framework will undoubtedly become more stringent in the future, and products that lack scientific substantiation for their health claims are expected to be removed from the market [3].

Probiotic Gl products, which are leading the way in clinical trials and marketing, can provide important lessons for use of probiotics in personal care products [5]. One example is the guidelines for probiotics in food generated by the Food and Agricultural Organization (FAO) and World Health Organization (WHO). After realizing the lack of consensus on the approach to determine efficiency and safety of probiotics, these international organizations convened to produce a guide that included recommendations on labeling and health claims for food products [72]. This is a resource that the stakeholders of personal care products can leverage while working through the various challenges mentioned above.

Cosmetics, which constitute a major component of the personal care industry, face a unique issue in complying with the definition of probiotics as viable organisms in their products. Under the legal framework of the FD\&C Act, there are guidelines on the number of live organisms permitted in products. Some have suggested the term "probiotic" is outdated and have proposed "pharmabiotics" (including inactivated microbiota or its components) as the term is more comprehensive and reflects the nature of products currently on the market $[3,5]$. However, FDA does not currently have a regulatory definition for "probiotic". A dialogue among stregulatory agencies, research communities, and industries would be beneficial in order to address this issue, as cosmetics affect a large number of consumers.

The current consensus is that probiotics have great potential to contribute to the promotion of human health. Much progress has been made in their application to the Gl system; however, scientific evidence from well-controlled studies is lagging behind the rapid rise of personal care products and consumers' interests. Collaboration and harmonization among stakeholders is paramount in moving this field forward. Some effort is already taking place; an example is the National Center for Complementary and Alternative Medicine, which is part of the National Institutes of Health's $(\mathrm{NIH})$ Probiotic and Prebiotic Working Group, a trans-agency effort focused on identifying gaps and challenges in probiotic and prebiotic research [1]. The continued advance in knowledge and data from the HMP enables the development of innovative approaches to utilize certain biomarkers in assessing the effects of probiotics and allows clinical studies to be conducted on a larger scale [3]. Industry should work with researchers and regulatory authorities if they wish to gain credibility for their products by addressing accurate labeling, good manufacturing practices, and rigorous quality control [72]. Because personal care products are an integral part of people's routines and habits, the potential benefits of probiotics, if substantiated, could have a positive impact on human lives.

\section{Disclaimer}

The information and conclusions presented in this manuscript do not represent new FDA policy nor do they imply an imminent change in existing policy.

\section{Competing interests}

The authors declare that they have no competing interests.

\section{Authors' contributions}

\begin{tabular}{|l|c|c|}
\hline Authors' contributions & JT & MJH \\
\hline Research concept and design & $\checkmark$ & $\checkmark$ \\
\hline Collection and/or assembly of data & $\checkmark$ & $\checkmark$ \\
\hline Data analysis and interpretation & -- & -- \\
\hline Writing the article & $\checkmark$ & $\checkmark$ \\
\hline Critical revision of the article & $\checkmark$ & $\checkmark$ \\
\hline Final approval of article & $\checkmark$ & $\checkmark$ \\
\hline Statistical analysis & -- & -- \\
\hline
\end{tabular}

Publication history

Editor: Janet Donaldson, Mississippi State University, USA. Senior Editor: Ester Grilli, University of Bologna, Italy. Received: 26-May-2015 Final Revised: 09-Jul-2015 Accepted: 20-Jul-2015 Published: 25-Jul-2015

\section{References}

1. National Center for Complementary and Alternative Medicine, National Institute of Health. Oral probiotics: an introduction. 2012. I Pdf

2. Goldin BR and Gorbach SL. Clinical indications for probiotics: an overview. Clin Infect Dis. 2008; 46 Suppl 2:S96-100; discussion S144-51. | Article | PubMed

3. Foligne $B$, Daniel $C$ and Pot $B$. Probiotics from research to market: the possibilities, risks and challenges. Curr Opin Microbiol. 2013; 16:284-92. | Article | PubMed

4. Teran C. Probiotic Technology. Active Concepts. 2011.

5. Klein M, Sanders ME, Duong T and Young HA. Probiotics: from bench to 
Huang et al. Microbiology Discovery 2015,

market. Ann N Y Acad Sci. 2010; 1212 Suppl 1:E1-14. | Article | PubMed

6. Weese JS. Evaluation of deficiencies in labeling of commercial probiotics. Can Vet J. 2003; 44:982-3. | PubMed Abstract | PubMed Full $\underline{\text { Text }}$

7. Krutmann J. Pre- and probiotics for human skin. Clin Plast Surg. 2012; 39:59-64. | Article | PubMed

8. Orellana J. My Cosmetic Product Contains Probiotics and Prebiotics. 2012. | Website

9. U.S. Food and Drug Administration (FDA). Cosmetics Safety Q\&A: Personal Care Products. 2015. I Website

10. U.S. Food and Drug Administration (FDA). Federal Food, Drug and Cosmetic Act (FD\&C Act) Regulatory Information. Sec. 201. [21 U.S.C. 321] Chapter II - Definitions. 2012. I Website

11. Gill SR, Pop M, Deboy RT, Eckburg PB, Turnbaugh PJ, Samuel BS, Gordon $\mathrm{JI}$, Relman DA, Fraser-Liggett CM and Nelson KE. Metagenomic analysis of the human distal gut microbiome. Science. 2006; 312:1355-9. | Article | PubMed Abstract | PubMed Full Text

12. Peterson J, Garges S, Giovanni M, McInnes P, Wang L, Schloss JA, Bonazzi V, McEwen JE, Wetterstrand KA, Deal C and Baker CC et al. The NIH Human Microbiome Project. Genome Res. 2009; 19:2317-23. | Article | PubMed Abstract | PubMed Full Text

13. Structure, function and diversity of the healthy human microbiome. Nature. 2012; 486:207-14. | Article | PubMed Abstract | PubMed Full $\underline{\text { Text }}$

14. National Human Genome Research Institute. NIH Human Microbiome Project defines normal bacterial makeup of the body. News \& Events. 2013. | Website

15. Grice EA, Kong HH, Conlan S, Deming CB, Davis J, Young AC, Bouffard GG, Blakesley RW, Murray PR, Green ED, Turner ML and Segre JA. Topographical and temporal diversity of the human skin microbiome. Science. 2009; 324:1190-2. | Article | PubMed Abstract | PubMed Full $\underline{\text { Text }}$

16. Costello EK, Lauber CL, Hamady M, Fierer N, Gordon JI and Knight R. Bacterial community variation in human body habitats across space and time. Science. 2009; 326:1694-7. | Article | PubMed Abstract | PubMed Full Text

17. Li K, Bihan M, Yooseph S and Methe BA. Analyses of the microbial diversity across the human microbiome. PLoS One. 2012; 7:e32118. | Article | PubMed Abstract | PubMed Full Text

18. Wylie KM, Truty RM, Sharpton TJ, Mihindukulasuriya KA, Zhou Y, Gao $\mathrm{H}$, Sodergren $\mathrm{E}$, Weinstock GM and Pollard KS. Novel bacterial taxa in the human microbiome. PLoS One. 2012; 7:e35294. | Article | PubMed Abstract | PubMed Full Text

19. Oh J, Conlan S, Polley EC, Segre JA and Kong HH. Shifts in human skin and nares microbiota of healthy children and adults. Genome Med. 2012; 4:77. | Article | PubMed Abstract | PubMed Full Text

20. Reid G, Younes JA, Van der Mei HC, Gloor GB, Knight R and Busscher HJ. Microbiota restoration: natural and supplemented recovery of human microbial communities. Nat Rev Microbiol. 2011; 9:27-38. | Article | PubMed

21. Grice EA and Segre JA. The human microbiome: our second genome. Annu Rev Genomics Hum Genet. 2012; 13:151-70. | Article | PubMed Abstract | PubMed Full Text

22. Kassinen A, Krogius-Kurikka L, Makivuokko H, Rinttila T, Paulin L, Corander J, Malinen E, Apajalahti J and Palva A. The fecal microbiota of irritable bowel syndrome patients differs significantly from that of healthy subjects. Gastroenterology. 2007; 133:24-33. | Article | PubMed

23. Manichanh C, Rigottier-Gois L, Bonnaud E, Gloux K, Pelletier E, Frangeul L, Nalin R, Jarrin C, Chardon P, Marteau P, Roca J and Dore J. Reduced diversity of faecal microbiota in Crohn's disease revealed by a metagenomic approach. Gut. 2006; 55:205-11. | Article | PubMed Abstract | PubMed Full Text

24. Turnbaugh PJ, Ley RE, Mahowald MA, Magrini V, Mardis ER and Gordon $\mathrm{Jl}$. An obesity-associated gut microbiome with increased capacity for energy harvest. Nature. 2006; 444:1027-31. | Article I PubMed

25. Cho I and Blaser MJ. The human microbiome: at the interface of health and disease. Nat Rev Genet. 2012; 13:260-70. | Article | PubMed Abstract | PubMed Full Text

26. Ridaura VK, Faith JJ, Rey FE, Cheng J, Duncan AE, Kau AL, Griffin NW, Lombard V, Henrissat B, Bain JR and Muehlbauer MJ et al. Gut microbiota from twins discordant for obesity modulate metabolism in mice. Science. 2013; 341:1241214. | Article | PubMed Abstract | PubMed Full Text

27. Smith MI, Yatsunenko T, Manary MJ, Trehan I, Mkakosya R, Cheng J, Kau AL, Rich SS, Concannon P, Mychaleckyj JC, Liu J, Houpt E, Li JV, Holmes E, Nicholson J, Knights D, Ursell LK, Knight R and Gordon JI. Gut microbiomes of Malawian twin pairs discordant for kwashiorkor. Science. 2013; 339:548-54. | Article | PubMed Abstract | PubMed Full $\underline{\text { Text }}$

28. Grice EA and Segre JA. The skin microbiome. Nat Rev Microbiol. 2011; 9:244-53. | Article | PubMed Abstract | PubMed Full Text

29. Holland KT and Bojar RA. Cosmetics: what is their influence on the skin microflora? Am J Clin Dermatol. 2002; 3:445-9. I PubMed

30. Gao Z, Tseng CH, Strober BE, Pei Z and Blaser MJ. Substantial alterations of the cutaneous bacterial biota in psoriatic lesions. PLoS One. 2008; 3:e2719. | Article | PubMed Abstract | PubMed Full Text

31. Cogen AL, Nizet $V$ and Gallo RL. Skin microbiota: a source of disease or defence? Br J Dermatol. 2008; 158:442-55. | Article | PubMed Abstract | PubMed Full Text

32. Grice EA and Segre JA. Interaction of the microbiome with the innate immune response in chronic wounds. Adv Exp Med Biol. 2012; 946:5568. | Article | PubMed Abstract | PubMed Full Text

33. Grice EA, Snitkin ES, Yockey LJ, Bermudez DM, Liechty KW and Segre $J A$. Longitudinal shift in diabetic wound microbiota correlates with prolonged skin defense response. Proc Natl Acad Sci U S A. 2010; 107:14799-804. | Article | PubMed Abstract | PubMed Full Text

34. Kong HH, Oh J, Deming C, Conlan S, Grice EA, Beatson MA, Nomicos E, Polley EC, Komarow HD, Murray PR, Turner ML and Segre JA. Temporal shifts in the skin microbiome associated with disease flares and treatment in children with atopic dermatitis. Genome Res. 2012; 22:850-9. | Article | PubMed Abstract | PubMed Full Text

35. Altoparlak U, Erol S, Akcay MN, Celebi F and Kadanali A. The time-related changes of antimicrobial resistance patterns and predominant bacterial profiles of burn wounds and body flora of burned patients. Burns. 2004; 30:660-4. | Article | PubMed

36. Citron DM, Goldstein EJ, Merriam CV, Lipsky BA and Abramson MA. Bacteriology of moderate-to-severe diabetic foot infections and in vitro activity of antimicrobial agents. J Clin Microbiol. 2007; 45:2819-28. | Article I PubMed Abstract I PubMed Full Text

37. Zarco MF, Vess TJ and Ginsburg GS. The oral microbiome in health and disease and the potential impact on personalized dental medicine. Oral Dis. 2012; 18:109-20. | Article | PubMed

38. Zaura E, Keijser BJ, Huse SM and Crielaard W. Defining the healthy "core microbiome" of oral microbial communities. BMC Microbiol. 2009; 9:259. | Article | PubMed Abstract | PubMed Full Text

39. Dewhirst FE, Chen T, Izard J, Paster BJ, Tanner AC, Yu WH, Lakshmanan A and Wade WG. The human oral microbiome. J Bacteriol. 2010; 192:5002 17. | Article | PubMed Abstract | PubMed Full Text

40. Wade WG. The oral microbiome in health and disease. Pharmacol Res. 2013; 69:137-43. | Article | PubMed

41. Liu B, Faller LL, Klitgord N, Mazumdar V, Ghodsi M, Sommer DD, Gibbons TR, Treangen TJ, Chang YC, Li S, Stine OC, Hasturk H, Kasif S, Segre D, Pop $M$ and Amar $S$. Deep sequencing of the oral microbiome reveals signatures of periodontal disease. PLoS One. 2012; 7:e37919. | Article | PubMed Abstract | PubMed Full Text

42. Mehanna N and Reid G. Effect of Meswak (Middle Eastern tree bark) on oral pathogens and potential for probiotic applications. J Med Food. 2010; 13:729-32. | Article | PubMed

43. Burton JP, Chilcott CN, Moore CJ, Speiser G and Tagg JR. A preliminary study of the effect of probiotic Streptococcus salivarius K12 on oral malodour parameters. J Appl Microbiol. 2006; 100:754-64. | Article | PubMed

44. Zahradnik RT, Magnusson I, Walker C, McDonell E, Hillman CH and 
Huang et al. Microbiology Discovery 2015,

Hillman JD. Preliminary assessment of safety and effectiveness in humans of ProBiora3, a probiotic mouthwash. J Appl Microbiol. 2009; 107:682-90. | Article | PubMed

45. Puch F, Samson-Villeger S, Guyonnet D, Blachon JL, Rawlings AV and Lassel T. Consumption of functional fermented milk containing borage oil, green tea and vitamin E enhances skin barrier function. Exp Dermatol. 2008; 17:668-74. | Article | PubMed

46. Schmidt C. Box 1: Whence Probiotics? Nature Biotechnology. 2013; 31:279-81. | Article

47. Walker R and Buckley M. Probiotic Microbes: the Scientific Basis. American Academic of Microbiology. 2006. | Article

48. Curz PM, Ibanez AL, Hermosillo OA and Saad HC. Use of probiotics in aquaculture. ISRN Microbiology. 2012: ID916845. | Article

49. Atarashi K, Tanoue T, Shima T, Imaoka A, Kuwahara T, Momose $Y$, Cheng G, Yamasaki S, Saito T, Ohba Y, Taniguchi T, Takeda K, Hori S, Ivanov, II, Umesaki $Y$, Itoh $K$ and Honda $K$. Induction of colonic regulatory $T$ cells by indigenous Clostridium species. Science. 2011; 331:337-41. | Article | PubMed Abstract | PubMed Full Text

50. Rohde $\mathrm{CL}$, Bartolini $\mathrm{V}$ and Jones N. The use of probiotics in the prevention and treatment of antibiotic-associated diarrhea with special interest in Clostridium difficile-associated diarrhea. Nutr Clin Pract. 2009; 24:33-40. | Article | PubMed

51. Lew $L C$ and Liong MT. Bioactives from probiotics for dermal health: functions and benefits. J Appl Microbiol. 2013; 114:1241-53. | Article | PubMed

52. de Vrese $M$ and Schrezenmeir J. Effects of Probiotics and Prebiotics: Preface. J Nutr. 2007; 137:739S. | Article

53. Sharp RR, Achkar JP, Brinich MA and Farrell RM. Helping patients make informed choices about probiotics: a need for research. Am J Gastroenterol. 2009; 104:809-13. | Article | PubMed Abstract | PubMed Full Text

54. Ouwehand AC, Batsman A and Salminen S. Probiotics for the skin: a new area of potential application? Lett Appl Microbiol. 2003; 36:327-31. | Article | PubMed

55. Drago L, lemoli E, Rodighiero V, Nicola L, De Vecchi E and Piconi S. Effects of Lactobacillus salivarius LS01 (DSM 22775) treatment on adult atopic dermatitis: a randomized placebo-controlled study. Int J Immunopathol Pharmacol. 2011; 24:1037-48. | Article | PubMed

56. Jensen MP, Meldrum S, Taylor AL, Dunstan JA and Prescott SL. Early probiotic supplementation for allergy prevention: long-term outcomes. J Allergy Clin Immunol. 2012; 130:1209-1211 e5. | Article | PubMed

57. Brouwer ML, Wolt-Plompen SA, Dubois AE, van der Heide S, Jansen DF, Hoijer MA, Kauffman HF and Duiverman EJ. No effects of probiotics on atopic dermatitis in infancy: a randomized placebo-controlled trial. Clin Exp Allergy. 2006; 36:899-906. | Article | PubMed

58. Brachkova MI, Duarte A and Pinto JF. Alginate films containing viable Lactobacillus plantarum: preparation and in vitro evaluation. AAPS PharmSciTech. 2012; 13:357-63. | Article | PubMed Abstract | PubMed Full Text

59. Elsevier Business Intelligence. Science of Beauty: Ganeden Claims "Highest Level" Proof for Anti-Aging Probiotic. Pharma \&Med Tech Business Intelligence. 2013. | Website

60. Hitchins AD, Gran TT and McCarron JE. Microbiological Methods for Cosmetics. In The BAM Council (Ed). Bacteriology Analytical Manual: U.S. Food and Drug Administration. 2004. | Book

61. Denyer SP. Development of Preservative Systems. $2^{\text {nd }}$ edition. In Baird SM (Ed), Microbial quality Assurance in Cosmetics, Toiletries and NonSterile Pharmaceuticals. 1996. 9:133-47. | Book

62. Crawford E. Probiotic Oral Care? Beneficial Microbes Spread to New Categories. Pharma \& Med Tech Business Intelligence. 2014. | Article

63. Jose JE, Padmanabhan S and Chitharanjan AB. Systemic consumption of probiotic curd and use of probiotic toothpaste to reduce Streptococcus mutans in plaque around orthodontic brackets. Am J Orthod Dentofacial Orthop. 2013; 144:67-72. | Article | PubMed

64. Suffield CT. New Designs for Health Probiotic Toothpaste - a Breakthrough to Oral Health. 2010. | Article
65. Jain $P$ and Sharma P. Probiotics and their efficacy in improving oral health: a review. J Applied Pharmaceutical Science. 2012; 2:151-63. | Pdf

66. US Food and Drug Administration (FDA). Federal Food, Drug, and Cosmetic Act (FD\&C Act). 2015. | Website

67. Guarner F, Sanders ME, Gibson G, Klaenhammer T, Cabana M, Scott K, Reid G, Delzenne NM, Fahey GC and Hill C. Probiotic and prebiotic claims in Europe: seeking a clear roadmap. Br J Nutr. 2011; 106:1765-7. | Article | PubMed

68. Starling S. EFSA slams door on probiotic health claims (again); prunes pass. NUTRA Ingredients. 2012. I Website

69. Brink M, Senekal M and Dicks LM. Market and product assessment of probiotic/prebiotic-containing functional foods and supplements manufactured in South Africa. S Afr Med J. 2005; 95:114-9. | Pdf | PubMed

70. ICMR-DBT guidelines for evaluation of probiotics in food. Indian J Med Res. 2011; 134:22-5. | Article | PubMed Abstract | PubMed Full Text

71. Ministry of Heath Labour and Welfare. Food for Specified Health Uses (FOSHU). 2014. | Article

72. Pineiro $\mathrm{M}$ and Stanton $\mathrm{C}$. Probiotic bacteria: legislative framework-requirements to evidence basis. J Nutr. 2007; 137:850S-3S. | Article | PubMed

\section{Citation}

Huang M-CJ and Tang J. Probiotics in personal care products. Microbiol Discov. 2015; 3:5.

http://dx.doi.org/10.7243/2052-6180-3-5 